\title{
What interventions are effective on reducing inequalities in maternal and child health in low- and middle-income settings? A systematic review
}

\author{
Beibei Yuan ${ }^{1,2^{*}}$, Mats Målqvist ${ }^{3}$, Nadja Trygg ${ }^{1}, X$ Q Qian ${ }^{4}$, Nawi Ng$^{5}$ and Sarah Thomsen ${ }^{1}$
}

\begin{abstract}
Background: The deadline for achieving Millennium Development Goals 4 and 5 is approaching, but inequalities between disadvantaged and other populations is a significant barrier for progress towards achieving these goals. This systematic review aims to collect evidence about the differential effects of interventions on different sociodemographic groups in order to identify interventions that were effective in reducing maternal or child health inequalities.

Methods: We searched the PubMed, EMBASE and other relevant databases. The reference lists of included reviews were also screened to find more eligible studies. We included experimental or observational studies that assessed the effects of interventions on maternal and child health, but only studies that report quantitative inequality outcomes were finally included for analysis.

Results: 22 articles about the effectiveness of interventions on equity in maternal and child health were finally included. These studies covered five kinds of interventions: immunization campaigns, nutrition supplement programs, health care provision improvement interventions, demand side interventions, and mixed interventions. The outcome indicators covered all MDG 4 and three MDG 5 outcomes. None of the included studies looked at equity in maternal mortality, adolescent birth rate and unmet need for family planning. The included studies reported inequalities based on gender, income, education level or comprehensive socioeconomic status. Stronger or moderate evidence showed that all kinds of the included interventions may be more effective in improving maternal or child health for those from disadvantaged groups.

Conclusion: Studies about the effectiveness of interventions on equity in maternal or child health are limited. The limited evidence showed that the interventions that were effective in reducing inequity included the improvement of health care delivery by outreach methods, using human resources in local areas or provided at the community level nearest to residents and the provision of financial or knowledge support to demand side.
\end{abstract}

\section{Background}

Most low- and middle-income countries have made significant advances in reducing maternal and child mortality rates, even though these countries are still faced with serious inequalities in maternal and child health between different segments of the populations.

\footnotetext{
* Correspondence: ybb5231@163.com

'Division of Global Health (IHCAR), Department of Public Health, Karolinska Institutet, Nobels väg 9, SE-171 77, Solna Stockholm, Sweden

${ }^{2}$ Peking University China Center for Health Development Studies, Mailbox 505, Xue Yuan Road 38, Beijing 100191, China

Full list of author information is available at the end of the article
}

For example, the overall maternal mortality ratio in China decreased from 64/100 000 in 1996 to 38/100 000 in 2008, but women in the poorest rural areas still had about 5 times higher risk of maternal mortality than women in urban areas until 2006 [1]. In Viet Nam the latest population census in 2009 showed that the under-five mortality rate decreased to $24 / 1000$, as compared to 58/1000 in 1990 [2], but ethnic minorities still have a higher risk of under-five and neonatal mortality compared to the general population [3,4]. Ghana has not performed well in achieving the MDGs 4 and 5 and the populations in the poorest quintile still use less

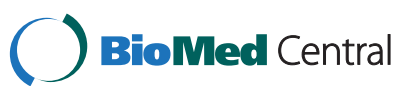

(c) 2014 Yuan et al.; licensee BioMed Central Ltd. This is an Open Access article distributed under the terms of the Creative Commons Attribution License (http://creativecommons.org/licenses/by/2.0), which permits unrestricted use, distribution, and reproduction in any medium, provided the original work is properly credited. 
maternal and child health care services, including skilled care at birth, delivery in a health facility and use of modern contraceptives [5]. The deadline for achieving the Millennium Development Goals (MDGs) 4 and 5 is approaching fast, but the inequity between disadvantaged and other populations is a significant barrier for this progress.

Different kinds of interventions aimed at reducing maternal and child mortality rates have been implemented in these low- and middle-income countries. Some interventions try to improve maternal and child health by improving material circumstances where women or children live, such as provision of nutrition supplementation [6]; some interventions try to improve the delivery of maternal and children health services, such as promotion of immunization by outreach campaign [7], training traditional birth attendant [8], and upgrading health facility infrastructure and equipment for health care [9]; some interventions target demand sides and remove the physical, financial or other barriers to access to maternal or child health services, such as , subsidies for use of health services [10], community based information, education and communication interventions [11]. Depending on their target population, these interventions can be categorized into universal or targeted. Universal approaches aim at the whole population, and targeted interventions are aimed at specific groups, usually the disadvantaged [12]. Universal interventions may have differential effects in different segments of populations, and it is possible that an intervention that is intended to improve health in the overall population may widen inequalities if its benefits are concentrated among the better-off [13]. Whether the poor and other disadvantaged populations benefit less or more from health policies and interventions has also become a concern of policymakers and researchers when assessing the effectiveness of these health interventions [12]. Assessment of different effects in different population strata is also relevant for targeted interventions, as the effects might be different across population subgroups even within a disadvantaged group. For example, nutrition interventions targeting poor populations may have different effects on boys and girls [6].

Although there are systematic reviews evaluating effects of some implemented interventions on improving maternal and child health outcomes [14-17], we have not found any systematic reviews that analyze whether these interventions helped or hampered reducing inequalities in maternal and child health. We carried out this systematic review to explore if the interventions aimed to improve maternal and child health have different effects on different sociodemographic groups in order to identify which interventions were effective in reducing maternal or child health inequalities.

\section{Method}

\section{Search strategy}

We identified original studies in all languages by searching nine databases about health, social science and grey literature and dissertation databases, which included Cochrane Library (search date: 2014.04.01), PubMed (2014.04.02), Embase (2012.04.05), PsycINFO (2012.04.06), Global health (2012.04.06), Popline (2012. 03.19), JSTOR (2012.03.29), ProQuest Dissertation \& Theses Database (2014.04.03) and ISI proceeding (2012.03.21). All databases were searched from their earliest collecting date to the search date. Terms about maternal or child health, equity or disadvantaged populations, low- and middle-income countries and intervention studies were combined in the search strategy. We first designed the search strategy in PubMed (Additional file 1), and then translated this search strategy into the other electronic databases using the appropriate controlled vocabulary as applicable and free-text terms. We also examined references of relevant studies and reviews to identify additional relevant papers.

\section{Inclusion criteria}

Inclusion criteria were discussed and agreed upon by all authors before starting this systematic review. We included experimental or observational study designs that assessed the effects of one or more kinds of interventions on maternal and child health, including randomized controlled trials, cluster randomized controlled trials, quasi-randomized controlled trials, controlled before-after studies, time series studies, before and after studies, cohort studies and case control studies.

We included all interventions designed to improve maternal and/or child health in any segment of the population (both universal interventions and targeted interventions) and/or those interventions specifically designed to reduce inequalities in maternal and/or child health exclusively in low and middle-income countries based on the World Bank List of Economies 2011 [18].

In terms of outcome measures, we only considered studies reporting the effects of interventions on official MDG 4 and 5 indicators, including under-five mortality rate, infant mortality rate, 1 year-old children immunized against measles, maternal mortality ratio, births attended by skilled health personnel, contraceptive use, adolescent birth rate, antenatal care coverage (at least one visit and at least four visits) and unmet need for family planning. Finally, only studies that report the inequalities outcomes were included. The inequalities outcomes could include quantitative descriptive difference for individuals or groups with different sociodemographic characteristics, absolute or relative concentration index, the slope or relative index of inequality [19], or any other measures used by authors for measuring change in 
inequalities after interventions. We used PROGRESS + categories as the sociodemographic indicators, which are: place of residence, race/ethnicity, occupation, gender, religion, education, socioeconomic status, social capital, age or disability [12].

\section{Study selection}

Two review authors (BY and MM) independently scanned titles and abstracts of all articles obtained from the initial search to exclude those studies which were not evaluation studies about effectiveness of interventions to improve maternal and children health. Review authors (BY, MM and NT) then continued screening the kept titles and abstracts (all intervention studies) to only include those studies about effectiveness on disadvantaged populations or equity, which were further screened by reading the full texts in order to only retrieve those studies evaluating effects of interventions on equity. During the selection process, all review authors resolved any disagreements on inclusion through discussion.

\section{Data extraction and quality assessment}

Key information such as intervention content, target population, study design, inequalities measure method, and maternal or children health outcome stratified by the sociodemographic characteristics specified in the PROGRESS criteria, was extracted from included full texts into an Excel file. The quality of each study was assessed by one review author (BY or NT) and checked by a second (MM or ST). We assessed study quality using a six-item checklist of quality criteria developed for the Effective Public Health Practice Project in Hamilton, Ontario [20]. In this checklist, six items include selection bias, study design, confounder control, blinding, data collection method and withdrawals and dropouts during study execution. Two review author firstly independently rated each item on a scale from "strong", "moderate" to "weak", and then jointly rated the methodology quality of whole study into "strong" (no weak rating for each item), "moderate" (one weak rating for each item) or "weak" (two or more weak ratings for each item). During this assessment process, all review authors resolved any disagreements on judgment through discussion.

\section{Data synthesis}

We synthesized the effects of interventions on equity using a narrative method. The narrative summary can be used in systematic reviews when meta-analysis is not possible because the heterogeneity in interventions or outcome measures or any other reasons. Typically this method involves the ordering or chronicling of evidence to produce an account of it [21]. In this review, we firstly categorized and summarized the characteristics of included studies, including intervention content, outcome indicators, and study methodological quality. Because our aim is to identify which interventions were effective in reducing maternal or child health inequalities and we are not committed to synthesize the magnitude of inequalities at this stage. So in the analysis, for each kind of intervention and dimension of inequality, we summarized if the intervention was more effective in more advantaged groups (increased inequality); the intervention was more effective in more disadvantaged groups (decreased inequality); or there was no social gradient in the effectiveness of the intervention (no increase or decrease). If the change in inequality reported by authors was statistically significant, we categorized it into "Increase" or "Decrease". Combined with the quality of studies, we analyzed if the conclusion was influenced by the studies' methodological quality.

\section{Results}

We found 14,551 references from 9 databases, and 11,754 were left after deleting duplicates, in which 1,106 were evaluation studies about interventions to improve maternal and child health. Of the 1,106 references, only 99 were related to the effectiveness of interventions on disadvantaged populations or different effects between different segments of populations. After reading the full texts of these potentially relevant studies, we finally included 22 articles which had result about effects of interventions on different segments of populations (Figure 1). Those studies only reporting effectiveness in disadvantaged populations, but not comparing different segments of populations were reported in another systematic review [22].

Table 1 shows the research content of the included studies. We found effectiveness on inequalities in the following five kinds of interventions: immunization campaigns, nutrition supplement programs, health care provision improvement interventions, demand side interventions, and mixed interventions.

The outcomes studied by the included studies cover all MDG 4 outcomes, but only three MDG 5 outcomes. The other MDG 5 outcomes, maternal mortality, adolescent birth rate, and unmet need for family planning were not reported. For the inequality dimension of outcomes, the included studies reported outcomes by gender, race or ethnicity, economic status, educational level and place of residence. The inequalities measure methods varied in different studies, and they can be roughly grouped into three categories: and the association analysis between intervention and outcomes being stratified by sociodemographic factors, interactions between sociodemographic indictors and intervention status being added in regression model, and the change in concentration index.

\section{Expanding immunization coverage campaign}

Five studies, one published in 1996 and four published after 2000 (2002-2011), evaluated immunization expanding 


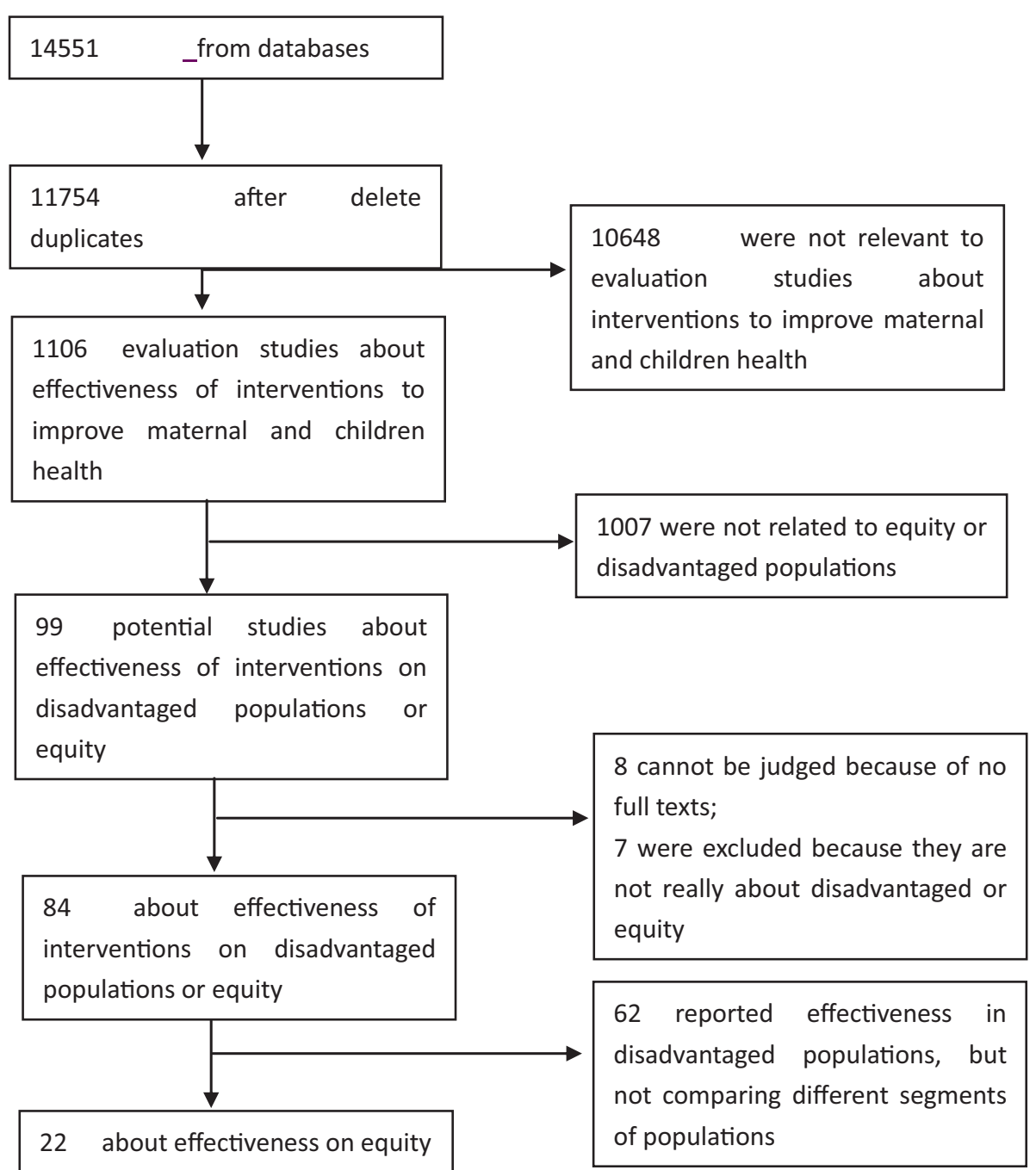

Figure 1 Study screening flow diagram.

interventions in Bangladesh [25,26,31], South Africa [28] and Zambia [7]. The interventions aimed to increase measles immunization rates through outreach immunization services provided by community health workers $[7,25]$ and widespread publicity to encourage and increase the availability of vaccinations [28]. Another two studies regarded measles vaccination as an intervention, and evaluated its effects on equity in under-five mortality rates [26,31]. The evidence from one strong study [25] and one moderate study [7] suggested that outreach immunization services may be more effective in improving measles immunization for those children whose mothers had lower educational backgrounds, those living in small rooms [25] and those living far from health facilities [7]. The same quality level of evidence showed that measles immunization could reduce the differences in child mortality between children living in different sizes of homes and between children with different socioeconomic status [26,31]. One weak study did not come to a clear conclusion on whether or not immunization publicity campaigns reduce inequality in measles immunization rates between different races [28] (Table 2).

\section{Nutrition supplements}

Four studies published between 2005 and 2011 evaluated nutrition supplements on under-five children or neonatal mortality in China [37], Guinea-Bissau [6,35] and Nepal [27]. In two studies the supplements targeted children aged 6 to 60 months [27,35]. One study targeted low birth weight neonates [8], and another targeted pregnant women until delivery [37]. The nutrition supplement interventions included Vitamin A supplements $[6,27,35]$, multiple micronutrients, and iron/folic acid 
Table 1 Description of included studies

\begin{tabular}{|c|c|c|c|c|c|}
\hline $\begin{array}{l}\text { Article and } \\
\text { country of study }\end{array}$ & Intervention type & MDG outcome & $\begin{array}{l}\text { Study design } \\
\text { and overall quality }\end{array}$ & $\begin{array}{l}\text { Inequality } \\
\text { dimension }\end{array}$ & Inequality measurement and outcomes \\
\hline \multirow{2}{*}{$\begin{array}{l}\text { Aquino } 2009[23] \\
\text { Brazil }\end{array}$} & \multirow{2}{*}{$\begin{array}{l}\text { Interventions to improve provision of maternal and } \\
\text { child health care services: Family Health Program } \\
\text { (Strengthening community health service provision) }\end{array}$} & \multirow{2}{*}{$\begin{array}{l}\text { MDG 4: Infant } \\
\text { and under-five } \\
\text { mortality }\end{array}$} & Ecological study & \multirow{2}{*}{$\begin{array}{l}\text { Socioeconomic } \\
\text { status }\end{array}$} & \multirow{2}{*}{$\begin{array}{l}\text { Fixed-Effects Models stratified by human development index } \\
\text { of a district; Reductions in infant mortality rates measured by } \\
\text { Risk Ratios after Family Health Program being more in lower } \\
\text { Human development index group }\end{array}$} \\
\hline & & & Moderate & & \\
\hline \multirow[t]{2}{*}{$\begin{array}{l}\text { Baqui } 2008[24] \\
\text { India }\end{array}$} & \multirow{2}{*}{$\begin{array}{l}\text { Interventions to improve provision of maternal and } \\
\text { child health care services: NGO facilitation of a } \\
\text { government community-based MCH program }\end{array}$} & \multirow{2}{*}{$\begin{array}{l}\text { MDG 5: Skilled } \\
\text { birth attendance } \\
\text { and antenatal } \\
\text { care visit }\end{array}$} & $\begin{array}{l}\text { Controlled before } \\
\text { and after study }\end{array}$ & \multirow[t]{2}{*}{ Asset/wealth } & \multirow{2}{*}{$\begin{array}{l}\text { Concentration indices }(\mathrm{Cl}) \text { calculated for intervention and } \\
\text { comparison districts at baseline and endline for each outcome; } \\
\text { The change of } \mathrm{Cl} \text { from baseline to endline in intervention } \\
\text { districts being significant, but not in comparison districts }\end{array}$} \\
\hline & & & Strong & & \\
\hline \multirow{2}{*}{$\begin{array}{l}\text { Benn } 2010[6] \\
\text { Guinea-Bissau }\end{array}$} & \multirow[t]{2}{*}{ Nutrition supplements: Vitamin A } & \multirow{2}{*}{$\begin{array}{l}\text { MDG 4: Infant } \\
\text { and under-five } \\
\text { mortality }\end{array}$} & Controlled trial & \multirow[t]{2}{*}{ Gender } & \multirow{2}{*}{$\begin{array}{l}\text { The differences in mortality between Vitamin A group and } \\
\text { Placebo group, and stratification by sex; mortality rate ratios } \\
\text { of vitamin A supplementation showing the supplementation } \\
\text { tended to be beneficial in boys but not in girls }\end{array}$} \\
\hline & & & Strong & & \\
\hline \multirow{2}{*}{$\begin{array}{l}\text { Bishai } 2002[25] \\
\text { Bangladesh }\end{array}$} & \multirow{2}{*}{$\begin{array}{l}\text { Expanding immunization coverage campaign: } \\
\text { Intensive outreach visits by community health workers }\end{array}$} & \multirow{2}{*}{$\begin{array}{l}\text { MDG 4: Measles } \\
\text { vaccination }\end{array}$} & Cohort study & \multirow{2}{*}{$\begin{array}{l}\text { Education, size } \\
\text { of living room }\end{array}$} & \multirow{2}{*}{$\begin{array}{l}\text { Interactions between socioeconomic status indictors and a } \\
\text { dummy variable for residence in intervention areas was } \\
\text { added in probit regressions; The effects of parents' education } \\
\text { and living size being both lessened in intervention areas }\end{array}$} \\
\hline & & & Strong & & \\
\hline \multirow{2}{*}{$\begin{array}{l}\text { Bishai } 2003[26] \\
\text { Bangladesh }\end{array}$} & \multirow{2}{*}{$\begin{array}{l}\text { Expanding immunization coverage campaign: } \\
\text { Measles vaccine }\end{array}$} & \multirow{2}{*}{$\begin{array}{l}\text { MDG 4: Infant } \\
\text { and under-five } \\
\text { mortality }\end{array}$} & Cohort study & \multirow{2}{*}{$\begin{array}{l}\text { Socioeconomic } \\
\text { status }\end{array}$} & \multirow{2}{*}{$\begin{array}{l}\text { Socio-economic differentials in mortality between the lowest } \\
\text { and highest socioeconomic status (SES) quintiles in a cohort } \\
\text { of vaccinated children and a control cohort; The mortality } \\
\text { ratio of lowest SES to highest in the control population being } \\
\text { significantly higher than it in the vaccinated population }\end{array}$} \\
\hline & & & Strong & & \\
\hline \multirow{2}{*}{$\begin{array}{l}\text { Bishai } 2005[27] \\
\text { Nepal }\end{array}$} & \multirow[t]{2}{*}{ Nutrition supplements: Vitamin A } & \multirow{2}{*}{$\begin{array}{l}\text { MDG 4: Infant } \\
\text { and under-five } \\
\text { mortality }\end{array}$} & Controlled trial & \multirow{2}{*}{$\begin{array}{l}\text { Gender, caste } \\
\text { and asset }\end{array}$} & \multirow{2}{*}{$\begin{array}{l}\text { The differences in mortality between boys and girls in Vitami } \\
\text { A group and placebo group; The difference in Vitamin A } \\
\text { group being less than the difference in placebo group }\end{array}$} \\
\hline & & & Strong & & \\
\hline \multirow[t]{2}{*}{$\begin{array}{l}\text { Dyer } 1996[28] \\
\text { South Africa }\end{array}$} & \multirow[t]{2}{*}{$\begin{array}{l}\text { Expanding immunization coverage campaign: } \\
\text { National immunization campaign }\end{array}$} & \multirow[t]{2}{*}{$\begin{array}{l}\text { MDG 4: Measles } \\
\text { vaccination }\end{array}$} & $\begin{array}{l}\text { Repeated cross- } \\
\text { sectional study }\end{array}$ & \multirow[t]{2}{*}{ Ethnicity } & \multirow{2}{*}{$\begin{array}{l}\text { The differences vaccination coverage between pre- and post } \\
\text { campaign, and stratified for race; The difference in Asians be } \\
\text { ing more than the differences in urban and rural blacks }\end{array}$} \\
\hline & & & Weak & & \\
\hline \multirow[t]{2}{*}{$\begin{array}{l}\text { Hatt } 2007[29] \\
\text { Indonesia }\end{array}$} & $\begin{array}{l}\text { Interventions to improve provision of maternal } \\
\text { and child health care services: A midwife in every }\end{array}$ & $\begin{array}{l}\text { MDG 5: Skilled } \\
\text { birth attendance }\end{array}$ & $\begin{array}{l}\text { Repeated cross- } \\
\text { sectional study }\end{array}$ & Asset/wealth & $\begin{array}{l}\text { Time-trend interactions with wealth quintile and urban/rural } \\
\text { residence was added into logistic regression; The Odd Ratios }\end{array}$ \\
\hline & & & Weak & & $\begin{array}{l}\text { showing that protessional attendance in low socioeconomic } \\
\text { status group increased more than those with higher } \\
\text { socioeconomic status }\end{array}$ \\
\hline $\begin{array}{l}\text { Hotchkis } 2011 \text { [30] } \\
\text { Nigeria, Uganda, }\end{array}$ & $\begin{array}{l}\text { Interventions to improve provision of maternal and } \\
\text { child health care services: Expansion of the private }\end{array}$ & $\begin{array}{l}\text { MDG 5: Modern } \\
\text { contraceptive }\end{array}$ & $\begin{array}{l}\text { Repeated cross- } \\
\text { sectional study }\end{array}$ & Asset/wealth & $\begin{array}{l}\text { Concentration indices differences between different survey } \\
\text { rounds; concentration indices overall showing decrease trend }\end{array}$ \\
\hline $\begin{array}{l}\text { Bangladesh and } \\
\text { Indonesia }\end{array}$ & & & Moderate & & \\
\hline Koenig 2001 [31] & Expanding immunization coverage campaign: & MDG 4: Infant & Cohort study & Ge tivel, & Interactions between socioeconomic status indictors and \\
\hline & & mortality & Moderate & $\begin{array}{l}\text { dwelling size } \\
\text { and education } \\
\text { levels }\end{array}$ & $\begin{array}{l}\text { vaccination for those from smaller household dwelling size } \\
\text { significantly exceeding that for those with bigger dwelling } \\
\text { size, but no significant results for other two dimensions } \\
\text { (gender and education level) }\end{array}$ \\
\hline
\end{tabular}

(gender and education leve)


Kozhimannil 2009 Demand side interventions: Health insurance [32] Phillipines

\section{program}

Masanja 2005 [33] Interventions to improve provision of maternal Tanzania and child health care services: Integrated management of Childhood Illness

Nasreen 2003 [34] Interventions to improve provision of maternal Bangladesh and child health care services: BRAC intervention (Providing preventive health, nutrition education and other primary care)

Nielsen 2005 [35] Nutrition supplements: Vitamin A

Guinea-Bissau

Pebley 1991 [36] Mixed interventions: Combined health-care and Indiana

Mixed interventions: Combin

Sasaki 2011 [7] Expanding immunization coverage campaign: Zambia Outreach immunization services

Zeng 2011 [37] Nutrition supplements: Multiple micronutrients China

Kamiya 2013 [38] Mixed interventions: Safe Motherhood Promotion Bangladesh Project including demand side intervention (community mobilization through participatory approaches) and intervention to improve service provision

Quayyum 2013 [39] Interventions to improve provision of maternal and Bangladesh child health care services: BRAC program's the intervention on improving Maternal, Neonatal and Child Survival (IMN CS)

MDG 5: Antenatal Repeated cross-

care attendance sectional study

Moderate

MDG 4: Measles vaccination

MDG 4: Infant and under-five mortality

MDG 4: Infant and under-five mortality

MDG 4: Infant and under-five mortality

MDG 4: Measles vaccination

MDG 4: Infant and under-five mortality

Controlled tria Strong

MDG 5: Skilled birth attendance and antenatal care visit

Controlled before and after study Strong

MDG 5: Skilled birth attendance and antenatal care visit and after study

Moderate Strong

Controlled before and after study

Moderate

Controlled trial Weak

Repeated crosssectional study

Moderate

Controlled befor and after study Strong
Asset, occupation and place of residence (rural/urban)

Controlled before Socioeconomic status Case control study

Education, occupation, economic condition, age

Education and income

Asset/wealth
Stratified logistic analyses by urban/rural, employment status, and wealth; In women in rurat areas, those in the lowest wealth tertile and those who are employed, the odds ratios being bigger and significant

Concentration indices differences from 1999 to 2002 in both intervention and control groups; The difference in concentration indices in intervention group reducing more

Stratified analysis for association between BRAC membership and neonatal death; For those mothers aged less and those fathers without wage, the relative risks of death being greater

in intervention groups, and no significant influence from economic condition and parents' literacy ethnicity, Vitamin A supplemented children compared with pre-wartime place of (no Vitamin A supplementation); the mortality risks being residence significantly reduced after war (Vitamin A supplemented) in the area pre-war disadvantage of families living and for those the area pre-war disadvantage of
with low mother education level

The changes in male/female mortality ratios from before to during the intervention in different interventions and contro groups; the male/female mortality ratios being increased more in intervention groups than change in control group

Distance to Two logistic regression analysis before and after the

health facilities introduction of outreach immunization services; Before the introduction of outreach services, longer distances to the service points being associated with lower measles immunization coverage, but not after the outreach services; no significant outcome for income

Analysis for association between interventions and mortality outcome stratified by household wealth index; in the poorest group Iron/folic acid supplement significantly being related lower early neonate mortality, the association being not significant in wealthier group

Interaction term, Income quartile $\times$ Project $\times$ Time was added in Difference-in-differences logistic regressions; Relative to the comparison site, significant increase in antenatal care for women belonging to lower income quartiles compared to those in the highest quartile in the project site, no significant outcome for skilled birth attendance

Asset/wealth The change in concentration index over time in both intervention and comparison areas; The concentration index being reduced more in the intervention areas 
Table 1 Description of included studies (Continued)

Amudhan $2013 \quad$ Mixed interventions: demand side interventions (conditional cash transfer scheme) and interventions to improve services provision (the strengthening of the primary health centre network)

Houweling 2013 Demand side interventions: Participatory women's

[41] Indian group intervention

Mosquera 2012 [42] Colombia

Interventions to improve provision of maternal and child health care services: Primary Health Care $(\mathrm{PHC})$ strategy
MDG 5: Skilled

Controlled before

and after study

Moderate

Controlled

before and

after study

Strong

MDG 4: Infant

and under-5 mor-

tality rate

MDG 4: Infant and under-five

Ecological study Weak

Weak
Socio-economic Subgroup analysis by socioeconomic status on institutional status: caste delivery rate; institutional delivery among disadvantaged

and education mothers increasing more compared with the increase among other groups
Socio-economic Separate random effects logistic regression, for the most and status: caste, less socio-economically marginalized groups; Odd Ratios

land ownership, showing that mortality reducing more in most marginalized literacy, and populations than the reduction in less marginalized populations asset ownership

Socio-economic Change in concentration indices for four child health outcomes status from before to after implementation of intervention; The variation in the concentration index observed between the two periods being positive 
Table 2 Effects of different interventions on inequalities

\begin{tabular}{|c|c|c|c|c|c|}
\hline & $\begin{array}{l}\text { Expanding immunization } \\
\text { coverage }\end{array}$ & Nutrition supplements & $\begin{array}{l}\text { Interventions to improve } \\
\text { health care provision }\end{array}$ & $\begin{array}{l}\text { Demand side } \\
\text { interventions }\end{array}$ & Mixed interventions \\
\hline \multirow[t]{5}{*}{ Measles immunization rate } & Education $\downarrow(++)$; & & Socioeconomic status $\downarrow(+)$ & & \\
\hline & Living area $\downarrow(++)$; & & & & \\
\hline & Ethnicity ? (-); & & & & \\
\hline & Income ? (+); & & & & \\
\hline & Distance to health facilities $\downarrow(+)$ & & & & \\
\hline \multirow[t]{8}{*}{ Under-five children mortality rate } & Living area $\downarrow(+)$; & Gender $\downarrow$ & Socioeconomic status $\downarrow(-)$; & & Gender $\downarrow(-)$ \\
\hline & Socioeconomic status $\downarrow(++)$ & $(++)$ & & & \\
\hline & & Castes $\downarrow$ & & & \\
\hline & Gender? (+); & $(++)$ & & & \\
\hline & Education ? (+) & Asset ? (++) & & & \\
\hline & & Places of residence $\downarrow(+)$; & & & \\
\hline & & Education $\downarrow(+)$; & & & \\
\hline & & Ethnicity ? (+) & & & \\
\hline \multirow[t]{5}{*}{ Infant mortality rate } & & Gender $\uparrow(++)$ & Socioeconomic status $\downarrow(+,-)$; & Socioeconomic status $\downarrow(++)$ & Gender $\downarrow(-)$ \\
\hline & & Wealth $\downarrow(++)$ & Occupation $\uparrow(++) ;$ & & \\
\hline & & & $\operatorname{Age} \uparrow(++) ;$ & & \\
\hline & & & Economic condition ? (++) & & \\
\hline & & & Education ? (++) & & \\
\hline \multirow[t]{3}{*}{ Antenatal care visit } & & & Wealth $\downarrow(++)$ & Places of residence $\downarrow(+)$ & Income $\downarrow(++)$ \\
\hline & & & & Asset $\downarrow(+)$ & \\
\hline & & & & Occupation $\uparrow(+)$ & \\
\hline \multirow[t]{2}{*}{ Skilled births attendance } & & & Wealth $\downarrow(++,-)$ & & Income ? (++) \\
\hline & & & & & Socioeconomic status $\downarrow(+)$ \\
\hline Contraceptive use & & & Wealth $\downarrow(+)$ & & \\
\hline
\end{tabular}

$\downarrow$ Inequity was reduced, $\uparrow$ Inequity was increased, ? No increase or decrease.

++Strong methodology quality; + Moderate methodology quality; - Week methodology quality. 
supplementation [37]. The evidence from the two studies with strong quality was inconsistent: in Nepal universal supplementation with vitamin A narrowed differentials in child deaths across gender [27], but in low birth weight neonates of Guinea-Bissau vitamin A supplementation had a significant negative effect on neonatal mortality in girls [6]. Vitamin A supplementation also proved to be effective in narrowing mortality differentials among castes, places of residence and mothers' education levels $[27,35]$. Zeng's study [37] with strong quality found that both multiple micronutrients and iron/folic acid supplementation had positive effects on neonatal mortality among the poorest in socioeconomic status, but had no significant effects in wealthier households.

\section{Interventions to improve provision of maternal and child health care services}

Eight studies published from 2003 to 2013 assessed the effects of different interventions to improve maternal and child health care provision in Bangladesh [30,34,39], Columbia [42], Brazil [23], India [24], Indonesia [29,30], Nigeria [30], Tanzania [33] and Uganda [30]. The interventions varied, including:

Integrated Management of Childhood Illness (IMCI), was implemented in Tanzania. In this intervention, the prevention and treatment of common childhood illnesses were combined into simple guidelines and messages for use in primary health facilities and communities. The study with moderate quality suggested that IMCI reduced inequalities in measles immunization rates between different socioeconomic quintiles [33].

The Family health program in Brazil used multiprofessional teams working under the principles of comprehensive care to provide permanent and systematic follow-up of a given number of families residing in a circumscribed area. Priority actions include promotion, prevention, and care for mothers and children. The moderate quality level of evidence showed this program in Brazil had greater effect in reducing infant mortality rate in municipalities with higher infant mortality rates and lower human development index scores [23].

The BRAC health program in Bangladesh provided preventive health and nutrition education, as well as immunization, family planning, pregnancy and reproductive health related care and basic curative services, which were delivered by voluntary community health workers selected from the women's credit group members by means of regular household visits. This intervention was found to have more effects in advantaged populations, including elder mothers' children and children whose father were waged laborers, because BRAC provided less attention to adolescent and households with lower income during implementation [34]. As a key element of BRAC health program, the selected community health workers providing intensive homebased maternal and newborn care was specifically evaluated by an controlled before and after study [39], and the evaluation showed that intervention resulted in the pro-poor increase in the utilization of antenatal care and trained attendants for home delivery.

Primay health care strategy in Columbia included a core program "Salud a su Casa". The program worked in the network of first-level facilities and public hospitals, and twelve hundred families were assigned to a multidisciplinary basic health care team. Basic health care teams either provided intra or extramural services. A study [27] found this intervention contributed the reductions of the inequality associated with socioeconomic status in child health outcomes, but this study provided weak evidence because it just analyzed the concentration curves change before and after the strategy implementation without control groups.

Training and posting a midwife in every village with specific responsibility for pregnancy, delivery and postpartum care was the intervention content of the Indonesian village midwife program which aimed to increase the proportion of deliveries managed by trained professionals, particularly among poor rural populations. This program resulted in increased professional attendance, with the greatest increases occurring among the poorest two income quintiles [29].

Collaboration between NGOs and the government on community-based maternal and child health care was implemented in Uttar Pradesh, India. This partnership emphasized use of existing infrastructure, training of community-based workers, home visits to promote behavior change, complete geographical coverage during pregnancy and postnatal period, creating support for community-based workers by recruiting community volunteers and strengthening supportive supervision. This intervention was proved by a strong study to be effective in reducing inequality in antenatal care check-up and medically trained birth attendant between families with different asset quintiles [24].

Private sector supply of modern contraceptives was expanded in Nigeria, Uganda, Bangladesh and Indonesia in order to improve the availability of reproductive health care supplies and services. The approach was criticized for potentially leading to increases in disparities in health care services utilization. But a study across these four countries evaluated this expansion and found that inequalities based on socioeconomic status showed a decrease trend in the four countries [30].

\section{Demand side interventions}

Two studies published between 2009 and 2013 evaluated the impact of demand side interventions on antenatal care visits and neonatal mortality rate in Philippines [32] and India [41]. 


\section{Health insurance program}

One study published in 2009 evaluated if the National health insurance program (PhilHealth program) in Philippines was effective in improving access to prenatal and delivery care. Subgroup analyses in this moderate quality study showed that this health insurance program could reduce inequalities; with the strongest impacts among women in rural areas, those in the lowest wealth tertile and those who were employed [32].

Community-based participatory intervention was a kind of participatory women's group intervention, in which the participatory groups met regularly, guided by a facilitator to discuss and identify maternal and newborn health problems. This intervention could help increase people's awareness and demand for maternal health services and then improve women's health-care seeking behaviors. This kind of intervention was also verified by strong evidence [41] to have stronger effectiveness on reduction of neonatal mortality rate among the most marginalized women.

\section{Mixed interventions}

Three studies published from 1990 to 2013 assessed how the mixed interventions improve child health and maternal health care utilization in India [36,40] and Bangladesh [38]. The contents of mixed interventions are varied, including:

\section{Combined health-care and nutrition service provision}

One study [36] published in 1990 assessed the effect of combinations of nutrition and health services provision interventions in India. This study included three intervention groups (one group with nutritional supplementation, one group with a health-care program and the other group with integration of nutrition with the health-care program) and one control group, and looked at which intervention was more successful in reducing excess female mortality. There was a substantial reduction in the gap between male and female mortality in all three treatment groups, while there was little change in the control villages. Among the treatment groups, the biggest reduction in excess female mortality was in the combined-services group, followed by the nutritionalservices group and the health-care group. However, this study was rated as weak in methodological quality because it lacked reporting on confounding factors and follow-up rates.

Safe Motherhoo Promotion Project (SMPP) was conducted in the Narsingdi district of Bangladesh. This intervention included community mobilization through participatory approaches and strengthening of organizational and personnel capacities for delivering emergency obstetric care (EmOC) at district and subdistrict level hospitals. A well-conducted controlled before and after study [38] provided strong evidence that this intervention reduced income inequalities in access to antenatal care, but has no significant impact on skilled birth attendants.

\section{Combined conditional cash transfer (CCT) and the} strengthening of the primary health centre (PHC) network Primary health centres (PHCs) being selected to provide obstetric care with additional resources and a conditional cash transfer scheme were implemented in a staggered manner in some areas of India. One study [40] evaluated the impact of each intervention and the combination of them on inequality in use of skilled birth delivery, and this moderate evidence showed that the combined interventions, especially strengthening of the PHC network added to CCT, could result in a bigger increase in institutional delivery among the disadvantaged than among others.

\section{Discussion and conclusion Principal findings}

This review comprehensively collected and assessed evidence about effects of interventions on maternal and child health in low- and middle-income countries, and focused on assessing the available evidence about the role of these interventions in tackling health inequalities. Overall, we found that the number of original studies assessing the effectiveness of health interventions on inequality is still limited. During the screening process, although we found 1,106 evaluation studies about effectiveness of interventions aimed at improving maternal and children health, only 22 reported quantitatively the effects on different segments of populations.

We found evidence from current limited original studies that immunization outreach campaigns can reduce inequalities in immunization rates across different levels of education, living area and distance to health facilities, and that measles immunization could help reduce socioeconomic inequalities in child mortality.

Well-conducted studies also found that nutrition supplementation could be more effective in reducing infant mortality among different kinds of disadvantaged groups. But the evidence with respect to differential effects of vitamin A supplement by gender are not consistent: for reducing mortality of children aged 6-60 months girls benefitted more in Nepal [27], but vitamin A supplementation was harmful for low-birth weight neonate girls in Guinea-Bissau [6]. The success of vitamin A supplement in reducing inequality is because public health interventions relying on door-to-door distribution of nutrition essentially overcome intra-household gender biases that could otherwise be prejudiced against girls. Failure of vitamin A supplementation in reducing inequality for neonates may be because of initial differences in 
vitamin A status (boys have lower retinol levels in their cord blood than do girls) or a negative interaction between immunomodulating micronutrients and the DTP vaccine [6].

Though the contents of health care provision interventions included in our review were different from each other, most of them were successful in reducing the inequalities in maternal health care utilization or child health outcomes, mainly because these interventions in several Asian and African countries all emphasized nutrition or primary health care provision at the community level. A review of equity in maternal, newborn, and child health interventions in 54 countries also found that interventions that are carried out at the community level tended to be more equitable than those that are usually conducted in health facilities [43]. But intervention content including primary health care provision at the community level did not mean it would result in improved equity. For example, in the BRAC program of Bangladesh advantaged populations benefited more because in the process of policy implementation not enough attention was paid to adolescent and lowincome populations [34].

Not like interventions aimed to improve delivery of immunization, nutrition or health services, another kind of intervention is to address the demand side barriers to maternal and children health services. For example health insurance and conditional cash transfer can reduce the economic barrier to health care accessibility; community participatory intervention targeted the problem of disadvantaged population usually lacking awareness on health problems or importance of health care. The evidence collected by this review verified the disadvantaged population benefited more from this kind of interventions. The reasons are that these interventions could achieve or tried to ensure the uptake of the intervention (insurance coverage or participatory meeting) being similar among different kinds of populations; and when the uptake was universal, the effective interventions usually had stronger effects on the disadvantaged populations [41].

Some interventions were combination of the above interventions, and the evaluation of these combined interventions could remind us that both provision improvement and demand side inventions are indispensable for reducing inequality. For example Amudhan' study [40] found that the impact of strengthening of the PHC network added to CCT on reduction of inequality was bigger than the impact of only CCT. This result showed that demand side subsidy works better if the delivery system is accessible. Kozhimannil' study [32] mainly found that PhilHealth insurance program contributed to the reduction of inequalities, but this study also mentioned that another provision improvement invention at the same period (exposure to midwife clinics) was not associated with significant changes in the use of prenatal care.

\section{Strengths and weaknesses of the available evidence}

There are prospective experimental designs or observational studies with control groups for most kinds of interventions we included. Based on the six-item quality criteria, only four studies were rated as weak in methodology. A challenge for non-experimental studies is how to differentiate the effects of different interventions implemented simultaneously, because maternal and children health can be influenced by many kinds of interventions, and in developing countries there are usually many kinds of development or health interventions at the same time. Despite this, authors often did not report other interventions or contextual factors that might have influenced the effects of the intervention.

Information about how the interventions were implemented would help policy-makers and readers better understand how interventions could be effective in reducing inequity. Though most of the included studies discussed the possible reasons for how interventions influenced inequalities in maternal or child health, few studies described the implementation process of interventions in detail. Process evaluations would improve readers' understandings of which components were actually implemented, and help policymakers understand the challenges and benefits of various components in an intervention [12].

\section{Strengths and weaknesses of the review}

We attempted to obtain both published and unpublished relevant studies, and we also tried to include a wide range of study designs in order not to miss useful evidence, because for some community interventions targeting maternal or child health it is difficult to conduct experimental studies. However, it is possible that we have not identified all relevant interventions for which the effects on inequalities have been explored, since we only found five categories of interventions from so many interventions having been implemented to improve maternal and child health in low- and middle-income countries.

This review aims to find which interventions were effective in reducing maternal or child health inequalities, so we focused more on the direction of the interventions' effect on inequality (i.e. if the intervention decreased or increased inequality), but not the extent of inequality changed by the interventions. Besides, it is also difficult to synthesize the quantitative outcome related to equity because the inequality outcome was measured differently in different studies: some used the change in concentration index after intervention [30,33]; 
some added the interaction between sociodemographic variables and intervention variables in a multivariate analysis model [29,31]; some used the difference in change of outcome with interventions between different social groups $[27,35,37]$.

Incorporating the heterogeneity in intervention, study design, study quality and study outcomes were challenges for this systematic review. To manage this we referred to Thomas's analysis method [13] in his systematic review to do descriptive synthesis in order to incorporate the interventions, the study outcomes, study quality and sociodemographic stratified for equity analysis. Thomas developed a novel graphic method to synthesize and display the balance of evidence to illustrate the possible different effects of the interventions. We only illustrated them in a table because for each intervention, each outcome and each dimension of equity, only one or two studies were found in this systematic review.

\section{Implications for policy and future research}

From this evidence, we find that the first most important characteristics of these interventions in reducing inequality is that they were all related to basic health care for pregnant women or children, including immunization and other preventive health services, treatment of common illnesses, nutrition education or direct nutrition supplements. Secondly, in terms of health care or nutrition provision approaches, these interventions focused on outreach methods (home visit and follow-up by health workers), making use of human resources in local areas, and provision of services at the community level nearest to residents. This kind of approach can overcome many barriers for disadvantaged populations to access health services and improve health status, like economic barriers, long distance to health facilities and limited knowledge about the importance of basic health care. Thirdly, another kind of inventions is to provide financial or knowledge support to demand side in order to reduce the above mentioned barriers to access health services. Consequently, for public interventions to reduce inequalities in maternal and child health, basic health care relying on door-to-door distribution by community health workers or direct support to demanders should be the critical elements. Even if these public health interventions took a universal coverage approach, they may still improve equity.

We have identified several gaps in the evidence base about interventions to reduce inequalities in maternal or child health. In particular, studies about the differential effects of interventions on maternal or child health by sociodemographic indicators are limited. Given that many universal or targeted interventions for achieving
MDG 4 or 5 have been implemented in low- and middle-income countries in recent years, more subgroup analyses should be conducted when evaluating these interventions in order to shed light on effects on inequalities [44]. Even for evaluations of targeted interventions, subgroup analysis to look at effects on inequalities can provide evidence about how to better design targeting methods used by these interventions. For example, the interventions targeting less-developed areas may not result in the really disadvantaged populations in these areas gaining more. Moreover, the contextual and implementation process information is very important for explaining how interventions influenced inequities and providing implication for policy design. However, we found that in the current evidence there was a lack of contextual information and implementation process information for interventions, which should be included in future research.

\section{Additional file}

Additional file 1: Search Strategy used in PubMed.

\section{Competing interests}

We declare that we have no conflicts of interest.

\section{Authors' contributions}

All authors have contributed to the production of this manuscript. All review authors discussed and contributed to conceptualization of this review and development of review protocol. BY, MM, NT and ST applied the inclusion criteria, data extraction and quality assessment. BY prepared the first draft and all other authors commented on and revised it. All authors read and approved the final manuscript.

\section{Acknowledgements}

This research was conducted under the "Evidence for Policy and Implementation" (EPI-4) project, funded by the Swedish International Development Cooperation Agency (Sida)

\section{Author details}

'Division of Global Health (IHCAR), Department of Public Health, Karolinska Institutet, Nobels väg 9, SE-171 77, Solna Stockholm, Sweden. ²Peking University China Center for Health Development Studies, Mailbox 505, Xue Yuan Road 38, Beijing 100191, China. IInternational Maternal and Child Health, Department of Women's and Children's Health, Uppsala University, University Hospital, Akademiska sjukhuset, Uppsala SE-751 85, Sweden ${ }^{4}$ School of Public Health, Fudan University, Shanghai 200032, China. ${ }^{5}$ Unit of Epidemiology and Global Health, Department of Public Health and Clinical Medicine, Faculty of Medicine, Umeå University, 90187 Umeå, Sweden.

Received: 9 July 2013 Accepted: 13 June 2014

Published: 21 June 2014

\section{References}

1. Feng XL, Zhu J, Zhang L, Song L, Hipgrave D, Guo S, Ronsmans C, Guo Y, Yang Q: Socio-economic disparities in maternal mortality in China between 1996 and 2006. BJOG 2010, 117(12):1527-1536.

2. Government of Viet Nam: 2009 Population and Housing Census: Major Findings. Hanoi: General Statistics Office; 2010.

3. Hoa DP, Nga NT, Målqvist M, Persson LA: Persistent neonatal mortality despite improved under-five survival: a retrospective cohort study in northern Vietnam. Acta Paediatr 2008, 97(2):166-170. 
4. Målqvist M, Nga NT, Eriksson L, Wallin L, Hoa DP, Persson LÅ: Ethnic inequity in neonatal survival: a case-referent study in northern Vietnam. Acta Paediatr 2011, 100(3):340-346.

5. Zere E, Kirigia JM, Duale S, Akazili J: Inequities in maternal and child health outcomes and interventions in Ghana. BMC Public Health 2012, $12: 252$.

6. Benn CS, Fisker AB, Napirna BM, Roth A, Diness BR, Lausch KR, Ravn H, Yazdanbakhsh M, Rodrigues A, Whittle H, Aaby P: Vitamin A supplementation and BCG vaccination at birth in low birthweight neonates: two by two factorial randomised controlled trial. BMJ 2010, 340:C1101.

7. Sasaki S, Igarashi K, Fujino Y, Comber AJ, Brunsdon C, Muleya CM, Suzuki H: The impact of community-based outreach immunisation services on immunisation coverage with GIS network accessibility analysis in peri-urban areas, Zambia. J Epidemiol Community Health 2011, 65(12):1171-1178

8. Sibley LM, Sipe TA, Barry D: Traditional birth attendant training for improving health behaviours and pregnancy outcomes. Cochrane Database Syst Rev 2012, 8, CD005460.

9. Olukoya A, Ogunyemi M, Akitoye C, Abudu O, Tijani MA, Epoyun AO, Ahabue CE, Shaba O: Upgrading obstetric care at a secondary referral hospital, Ogun State, Nigeria. Int J Gynecol Obstet 1997, 59(Suppl 2):67-74.

10. Rasella D, Aquino R, Santos CA, Paes-Sousa R, Barreto ML: Effect of a conditional cash transfer programme on childhood mortality: a nationwide analysis of Brazilian municipalities. Lancet 2013, 382(9886):57-64.

11. Gummi FB, Hassan M, Shehu D, Audu L: Community education to encourage use of emergency obstetric services, Kebbi State, Nigeria. Int I Gynecol Obstet 1997, 59(Suppl 2):191-200.

12. Tugwell $P$, Petticrew $M$, Kristjansson $E$, Welch $V$, Ueffing $E$, Waters $E$, Bonnefoy J, Morgan A, Doohan E, Kelly MP: Assessing equity in systematic reviews: realising the recommendations of the Commission on Social Determinants of Health. BMJ 2010, 341:c4739.

13. Thomas S, Fayter D, Misso K, Ogilvie D, Petticrew M, Sowden A, Whitehead M, Worthy G: Population tobacco control interventions and their effects on social inequalities in smoking: systematic review. Tob Control 2008, 17:230-237.

14. Nyamtema AS, Urassa DP, van Roosmalen J: Maternal health interventions in resource limited countries: a systematic review of packages, impacts and factors for change. BMC Pregnancy Childbirth 2011, 11:30

15. Lassi ZS, Haider BA, Bhutta ZA: Community-based intervention packages for reducing maternal and neonatal morbidity and mortality and improving neonatal outcomes. Cochrane Database Syst Rev 2010, 11, CD007754.

16. Pattinson RC, Say L, Makin JD, Bastos MH: Critical incident audit and feedback to improve perinatal and maternal mortality and morbidity. Cochrane Database Syst Rev 2005, 4, CD002961.

17. Lewin S, Munabi-Babigumira S, Glenton C, Daniels K, Bosch-Capblanch X, van Wyk BE, Odgaard-Jensen J, Johansen M, Aja GN, Zwarenstein M, Scheel IB: Lay health workers in primary and community health care for maternal and child health and the management of infectious diseases. Cochrane Database Syst Rev 2010, 3, CD004015.

18. World Bank: World Bank List of Economies 2011. http://libraries.acm.org/sites/ default/files/Jan\%202011\%20World\%20bank\%20list\%20of\%20Economies. PDF. (accessed Oct 1, 2011).

19. Barros AJD, Victora CG: Measuring coverage in $\mathrm{MNCH}$ : determining and interpreting inequalities in coverage of maternal, newborn, and child health interventions. PLoS Med 2013, 10(5):e1001390.

20. Thomas H: Quality Assessment Tool for Quantitative Studies. Hamilton, Ontario: Effective Public Health Practice Project; 2003. http://www.ephpp.ca/ PDF/Quality\%20Assessment\%20Tool_2010_2.pdf. (accessed Oct 1, 2011).

21. Dixon-Woods M, Agarwal S, Jones D, Young B, Sutton AJ: Synthesising qualitative and quantitative evidence: a review of possible methods. $J$ Health Serv Res Policy 2005, 10(1):45-53.

22. Målqvist M, Yuan B, Trygg N, Selling K, Thomsen S: Targeted interventions for improved equity in maternal and child health in low- and middleincome settings: a systematic review and meta-analysis. PLOS ONE 2013, 8(6):e66453. doi:10.1371/journal.pone.0066453.

23. Aquino R, de Oliveira NF, Barreto ML: Impact of the family health program on infant mortality in Brazilian municipalities. Am J Public Health 2009, 99(1):87-93.

24. Baqui AH, Rosecrans AM, Williams EK, Agrawal PK, Ahmed S, Darmstadt GL, Kumar V, Kiran U, Panwar D, Ahuja RC, Srivastava VK, Black RE, Santosham M:
NGO facilitation of a government community-based maternal and neonatal health programme in rural India: improvements in equity. Health Policy Plan 2008, 23(4):234-243

25. Bishai D, Suzuki E, McQuestion M, Chakraborty J, Koenig M: The role of public health programmes in reducing socioeconomic inequities in childhood immunization coverage. Health Policy Plan 2002, 17(4):412-419.

26. Bishai $D$, Koenig M, Ali Khan M: Measles vaccination improves the equity of health outcomes: evidence from Bangladesh. Health Econ 2003, 12(5):415-419.

27. Bishai D, Kumar KCS, Waters H, Koenig M, Katz J, Khatry SK, West KP Jr: The impact of vitamin A supplementation on mortality inequalities among children in Nepal. Health Policy Plan 2005, 20(1):60-66.

28. Dyer JJ, Naidoo KN, Knight S, Mjekevu T, Munro G, Robinson A: Effect of an immunisation campaign in Nataland KwaZuluon vaccination coverage rates, 1990-1991. S Afr Med J 1996, 86:158-161.

29. Hatt L, Stanton C, Makowiecka K, Adisasmita A, Achadi E, Ronsmans C: Did the strategy of skilled attendance at birth reach the poor in Indonesia? Bull World Health Organ 2007, 85(10):774-782

30. Hotchkiss DR, Godha D, Do M: Effect of an expansion in private sector provision of contraceptive supplies on horizontal inequity in modern contraceptive use: evidence from Africa and Asia. Int J Equity Health 2011, 10(1):33.

31. Koenig AM, Bishai D, Ali Khan M: Health interventions and health equity: the example of measles vaccination in Bangladesh. Popul Dev Rev 2001, 27(2):283-302.

32. Kozhimannil KB, Valera MR, Adams AS, Ross-Degnan D: The population-level impacts of a national health insurance program and franchise midwife clinics on achievement of prenatal and delivery care standards in the Philippines. Health Policy 2009, 92(1):55-64.

33. Masanja H, Schellenberg JA, de Savigny D, Mshinda H, Victora CG: Impact of Integrated Management of Childhood IIIness on inequalities in child health in rural Tanzania. Health Policy Plan 2005, 20(Suppl 1):i77-i84.

34. Nasreen EH, Bhuiya A, Ahmed MS, Chowdhury M: Women Focused Development Intervention Reduces Neonatal Mortality in Rural Bangladesh: A Study of the Pathways of Influence, 10th Asian Conference on Diarrhoeal Diseases and Nutrition (ASCODD), Scientific Session 20: Neonatal Health and Diarrhoeal Disease 3; 2003.

35. Nielsen J, Benn CS, Balé C, Martins C, Aaby P: Vitamin A supplementation during war-emergency in Guinea-Bissau 1998-1999. Acta Trop 2005, 93(3):275-282

36. Pebley AR, Amin S: The impact of a public-health intervention on sex differentials in childhood mortality in rural Punjab, India. Health Transit Rev 1991, 1(2):143-169.

37. Zeng $L$, Yan $H$, Cheng Y, Dibley MJ: Modifying effects of wealth on the response to nutrient supplementation in pregnancy on birth weight, duration of gestation and perinatal mortality in rural western China: double-blind cluster randomized controlled trial. Int J Epidemiol 2011, 40(2):350-362

38. Kamiya $Y$, Yoshimura $Y$, Islam MT: An impact evaluation of the safe motherhood promotion project in Bangladesh: evidence from Japanese aid-funded technical cooperation. Soc Sci Med 2013, 83:34-41.

39. Quayyum Z, Khan MN, Quayyum T, Nasreen HE, Chowdhury M, Ensor T: "Can community level interventions have an impact on equity and utilization of maternal health care" - evidence from rural Bangladesh. Int J Equity Health 2013, 12:22. doi:10.1186/1475-9276-12-22.

40. Amudhan S, Mani K, Rai SK, Pandav CS, Krishnan A: Effectiveness of demand and supply side interventions in promoting institutional deliveries-a quasi-experimental trial from rural north India. Int J Epidemiol 2013, 42(3):769-780.

41. Houweling TA, Tripathy P, Nair N, Rath S, Rath S, Gope R, Sinha R, Looman CW, Costello A, Prost A: The equity impact of participatory women's groups to reduce neonatal mortality in India: secondary analysis of a cluster-randomised trial. Int J Epidemiol 2013, 42(2):520-532.

42. Mosquera PA, Hernández J, Vega R, Martínez J, Labonte R, Sanders D, San Sebastián M: The impact of primary healthcare in reducing inequalities in child health outcomes, Bogotá-Colombia: an ecological analysis. Int J Equity Health 2012, 11:66. doi:10.1186/1475-9276-11-66.

43. Barros AJ, Ronsmans C, Axelson H, Loaiza E, Bertoldi AD, França GV, Bryce J, Boerma JT, Victora CG: Equity in maternal, newborn, and child health 
interventions in Countdown to 2015: a retrospective review of survey data from 54 countries. Lancet 2012, 379:1225-1233.

44. Östlin P, Schrecker T, Sadana R, Bonnefoy J, Gilson L, Hertzman C, Kelly MP, Kjellstrom T, Labonté R, Lundberg O, Muntaner C, Popay J, Sen G, Vaghri Z Priorities for research on equity and health: towards an equity-focused health research agenda. PLoS Med 2011, 8(11):e1001115.

doi:10.1186/1471-2458-14-634

Cite this article as: Yuan et al:: What interventions are effective on reducing inequalities in maternal and child health in

low- and middle-income settings? A systematic review. BMC Public Health 2014 14:634.

\section{Submit your next manuscript to BioMed Central and take full advantage of:}

- Convenient online submission

- Thorough peer review

- No space constraints or color figure charges

- Immediate publication on acceptance

- Inclusion in PubMed, CAS, Scopus and Google Scholar

- Research which is freely available for redistribution 